\title{
The risk of asthma in relation to occupational exposures: a case-control study from a Swedish city
}

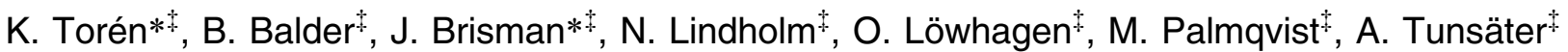

The risk of asthma in relation to occupational exposures: a case-control study from a Swedish city. K. Torén, B. Balder, J. Brisman, N. Lindholm, O. Löwhagen, M. Palmqvist, A. Tunsäter. (C)ERS Journals Ltd 1999.

ABSTRACT: The purpose of this study was to estimate the risk of adult asthma in relation to certain occupational exposures.

The study was designed as a case-control study in Göteborg, including 321 subjects with asthma, born between 1926 and 1970 . Controls $(n=1,459)$ were randomly selected from the same area from registers of the 1986 population. Questionnaire information was collected in 1996, and included occupational exposures and smoking habits. Odds ratios were calculated for exposure before asthma onset, stratified by sex and ageclass.

The highest risks for asthma were associated with exposure to grain dust (odds ratio (OR) 4.2, 95\% confidence interval (CI) 1.6-10.7) and flour dust (OR 2.8, 95\% CI 1.17.2). Among males, significantly increased risks were observed after exposure to flour dust, welding fumes, man-made mineral fibres, and solvents. Among females, increased risks for asthma were associated with exposures to paper dust and textile dust. In logistic regression models controlling for age, smoking, sex and interacting exposures, increased risks were seen for welding fumes (OR 2.0, 95\% CI 15-3.4), manmade mineral fibres (OR 2.6, 95\% CI 1.4-7.3) and solvents (OR 2.2, 95\% CI 1.2-3.2). The fraction of asthma attributed to occupational exposures after adjusting for sex, smoking and age was $11 \%(95 \%$ CI $7-14 \%)$.

In conclusion, exposure to welding fumes, man-made mineral fibres, solvents and textile dust is associated with increased risk for asthma.

Eur Respir J 1999; 13: 496-501.
*Section of Occupational Medicine, ${ }^{+} \mathrm{Sec}-$ tion of Respiratory Medicine and Allergology, Sahlgrenska University Hospital, Göteborg, Sweden.

Correspondence: K. Torén

Section of Occupational Medicine

Sahlgrenska University Hospital

St Sigfridsgatan 58

S-412 66 Göteborg

Sweden

Fax: 4631409728

Keywords: Asthma

occupational

questionnaires

retrospective

welding

Received: April 231998

Accepted after revision September 271998

This study was supported by the Swedish Council for Worklife Research and the Herman Kreftings Fund for Asthma Research.
A multitude of occupational exposures can cause asthma. Exposure to various synthetic chemicals, such as isocyanates, or agents of biological origin is associated with risk for occupational asthma. Our knowledge of the risk associated with occupational exposures in the general population is, however, limited. Most studies are case reports, register-based case-series or investigations of certain occupational cohorts with predefined exposure. The authors are aware of a few population-based studies [1-5], two hospital-based case-referent studies [6, 7] and two studies in a cohort of members of American health maintenance organizations $[8,9]$.

One major problem in population-based and/or casereferent studies of asthma is the assessment of exposure. Many types of exposures are scattered across different occupations, and job titles are poor indicators of occupational exposure. An alternative method is to ask the subjects whether they have been exposed to particular substances and to then use their responses as the variables for analysis [10].

In a previous population-based case-referent study, the authors used the method of self-reported exposure [11]. An increased risk for asthma associated with occupational exposure to flour dust, textile dust, welding fumes and certain reactive chemicals was found.
In this case-control study, another sample of asthmatics and controls was investigated, using a questionnaire similar to the previous study. This permitted the authors to investigate whether the increased risks observed in the previous study would also show up in this sample. Hence, the aim of the present study was to investigate the risk for adult asthma in relation to exposure to certain occupational exposures.

\section{Methods}

The study was performed in 1996, in the city of Göteborg, Sweden and adjacent communities. This is an area with a predominance of mechanical industries such as car manufacturers and shipyards. The study originally included 420 adult subjects with recent-onset asthma, aged 18-60 yrs (born 1926-1970) and identified from 19831986 in the Environment and Asthma in Göteborg (MASTIG) study. The case sample has been described previously [12], but briefly the asthmatics were identified by registering all subjects seeking medical care for asthma and asthma-like symptoms that started during 1983-1986. Persons with an earlier history of asthmatic symptoms must have been free from symptoms and medication for at 
least $5 \mathrm{yrs}$ to be included. These subjects were further investigated at the Section of Allergology, resulting in a population of 420 asthmatics. By 1996, seven asthmatics were deceased and six had moved abroad. Hence, the study included 407 cases with asthma.

A random sample of 2,000 subjects from the same area, born between 1926 and 1970, served as controls. Although the selection of controls was performed in 1996, they were from the population register of 1986. By 1996, 96 controls were deceased or had moved abroad. Hence, the study was performed on 1,904 controls. The cases in the current study were excluded from the control population. However, as it was a random population sample it most probably contained other subjects with asthma and asthma-like symptoms.

For an asthma diagnosis, a typical history was required (1), combined with at least one of the following (2-4) criteria [12]. 1) A typical history of asthma, meaning that at least three of the four following criteria were fulfilled: attacks of dyspnoea; wheezing; dyspnoea and cough induced by asthma trigger; or symptom relief using bronchodilators. 2) At least three amplitude differences in peak expiratory flow (PEF) variations of at least $20 \%$ during two weeks of registration. 3) Forced expiratory volume in one second (FEV1) increased $\geq 15 \%$ after inhalation of $\beta_{2^{-}}$ bronchodilators or after two weeks treatment with oral steroids. 4) Provocative concentration of methacholine causing a $20 \%$ fall in FEV1 $\left(\mathrm{PC}_{20}\right) \leq 4 \mathrm{mg} \cdot \mathrm{mL}^{-1}$ at a methacholine challenge test.

The case and controls were investigated in 1996, with a comprehensive questionnaire that included items regarding occupational exposures, certain occupations, occupational history, respiratory symptoms and smoking habits. The types of exposures/occupations asked about were selected for a variety of reasons. Firstly, the $a$ priori hypothesis that there was an increased risk for asthma after exposure to certain low molecular weight agents was tested, by asking about exposure to rapid glues (acrylates), paint hardeners (isocyanates), and welding fumes (metals). Secondly, the hypothesis that exposure to dust, both organic and inorganic, fumes and irritants may increase the risk for asthma was tested. Thirdly, questions were asked about flour dust, grain dust and laboratory animals, as "positive" controls.

The classification of the subjects' occupational exposures was based on self-reporting of certain exposures. The questions regarding occupational exposures were worded as follows: "In your work, have you been exposed to...?", "If 'yes', between which years...?". Altogether, questions were asked in reference to 25 types of occupational exposure and to two occupations (table 1).

Among cases the symptoms started in 1983 for $34 \%$, in 1984 for $24 \%$, in 1985 for $31 \%$ and in 1986 for $11 \%$. Even if a case reported symptoms starting in a certain year, the disease may have started earlier. Hence, for a case to be classified as exposed, the exposure period must be reported 2 yrs before the reported start of symptoms. The controls must report exposure in 1983 to be classified as exposed. In response to questions about the duration of the different types of exposures, many subjects reported more than one type of exposure during their exposure period.

The questionnaire was mailed to 407 cases and 1,904 controls. After two reminders, 321 cases $(79 \%)$ and 1,459 controls (77\%) responded. Age, sex distribution and smoking habits are presented in table 2 .
Table 1. - Wording of questions regarding self-assessed occupational exposures

\begin{tabular}{lcc}
\hline Exposure/occupational & \multicolumn{2}{c}{ Prevalence \% } \\
\cline { 2 - 3 } & Males & Females \\
\hline Have you been exposed to: & & \\
welding fumes? & 10.7 & 0.4 \\
mineral dust? & 6.2 & 0.1 \\
man-made mineral fibres? & 5.7 & - \\
asbestos? & 4.9 & 0.3 \\
grain dust? & 1.1 & 0.1 \\
flour dust? & 1.1 & 0.4 \\
wood dust? & 6.4 & 0.5 \\
paper dust? & 6.4 & 5.4 \\
textile dust? & 1.9 & 4.7 \\
sulphur dioxide? & 1.1 & 0.4 \\
chlorine? & 1.0 & 0.4 \\
strong acids? & 2.5 & 1.6 \\
formaldehyde? & 1.3 & 1.9 \\
fire fumes? & 1.9 & 0.1 \\
engine exhaust? & 13.5 & 2.9 \\
solvents? & 11.4 & 2.9 \\
ammonia? & 1.5 & 2.4 \\
Have you worked with? & & \\
soldering? & 6.7 & - \\
grinding? & 8.0 & 1.4 \\
rapid glues? & 4.4 & 1.1 \\
paint hardeners? & 2.6 & 0.4 \\
cutting oils/fluids? & 4.1 & 0.3 \\
laboratory animals? & 0.1 & - \\
tanning? & 0.1 & 0.1 \\
rubber chemicals? & 1.3 & 0.1 \\
Have you worked as a: & & 6.2 \\
cleaner? & 1.9 & 1.1 \\
hairdresser? & - & \\
\hline Al & & \\
& &
\end{tabular}

All questions were followed by "If 'yes' between which years?". The prevalence of exposure among controls $(n=1,464)$ is given.

\section{Statistical analyses}

The material was stratified by sex and age-class, and odds ratios (OR) were calculated according to MantelHaenszel. Only exposures with five or more exposed cases were considered in the final analysis $(n=20)$. If the number of exposed cases exceeded 20, stratification by smoking habits (never-smoker/ever-smoker) was added. Confidence intervals $(95 \% \mathrm{CI})$ were calculated with the test-based method [13].

Logistic regression analysis was applied to adjust for interactions between different exposures and to control for potential confounders. The SAS statistical package (version 6.11; SAS Institute, Cary, NC, USA) was used for the

Table 2. - Description of the study population, i.e. the cases and controls

\begin{tabular}{lrrrrrr}
\hline & \multicolumn{2}{c}{ Males } & & \multicolumn{2}{c}{ Females } \\
\cline { 2 - 3 } \cline { 6 - 6 } & $\begin{array}{c}\text { Cases } \\
\mathrm{n}=126\end{array}$ & $\begin{array}{c}\text { Controls } \\
\mathrm{n}=721\end{array}$ & & $\begin{array}{c}\text { Cases } \\
\mathrm{n}=195\end{array}$ & $\begin{array}{c}\text { Controls } \\
\mathrm{n}=738\end{array}$ \\
\hline Age yrs & 45.7 & 46.1 & & 44.1 & 46.0 \\
Never-smokers \% & 46.0 & 38.1 & & 44.6 & 39.2 \\
Exsmokers \% & 15.1 & 21.9 & & 19.5 & 25.7 \\
Current smokers \% & 37.3 & 36.9 & & 33.8 & 30.8 \\
Not reported & 1.6 & 3.1 & & 2.1 & 4.3 \\
\hline
\end{tabular}


analyses, and OR with 95\% CI were estimated [13]. The regression models were adjusted for sex, age-class and smoking (never-smoker/ever-smoker).

The attributable proportion (AP) was calculated as the proportion of all cases, occurring in a mixed population of exposed and unexposed individuals, which is attributable to exposure as $\mathrm{AP}=(\mathrm{OR}-1) \times \mathrm{P} / \mathrm{OR}$, where $\mathrm{P}$ is the prevalence of exposure among the cases [14]. Exposure was defined as exposures to factors judged to cause asthma. This decision was based on the literature and the present results. The following exposures were selected: welding fumes, grain dust, flour dust, textile dust, laboratory animals and paint hardeners (isocyanates). The estimates of AP were derived with a $95 \% \mathrm{CI}$, stratified for age, smoking and sex.

\section{Results}

With sexes merged, the risks of asthma for different exposure categories are shown in table 3 . The highest risks were observed among those exposed to well-known risk factors for occupational asthma, such as grain dust (OR $4.2,95 \%$ CI 1.6-10.7) and flour dust (OR 2.8, 95\% CI 1.1-7.2). Increased risk was also associated with exposure to welding fumes, man-made mineral fibres, paper dust, textile dust and solvents. When stratification for smoking was added, the risk estimates for asthma changed only marginally.

The risk estimates are shown in table 4, separated by sex. Among males, increased risks were associated with reported exposure to flour dust (OR 3.6, 95\% CI 1.310.4), man-made mineral fibres (OR 2.3, 95\% CI 1.2-4.2), solvents (OR 2.1, 95\% CI 1.3-3.5) and welding fumes (OR 2.0, 95\% CI 1.2-3.3). Among females, increased risks were associated with exposure to paper dust (OR

Table 3. - Risk for asthma according to occupational exposure

\begin{tabular}{llr}
\hline Exposure & Odds ratio & $\mathrm{n}$ \\
\hline Welding fumes & $2.0(1.2-3.2)$ & 26 \\
Soldering & $1.2(0.6-2.5)$ & 9 \\
Grinding & $1.2(0.7-2.2)$ & 15 \\
Cutting fluids & $1.5(0.7-3.2)$ & 9 \\
Mineral dust & $1.1(0.5-2.4)$ & 9 \\
Man-made mineral fibres & $2.3(1.2-4.2)$ & 15 \\
Asbestos & $1.9(1.0-3.7)$ & 12 \\
Grain dust & $4.2(1.6-10.7)$ & 7 \\
Flour dust & $2.8(1.1-7.2)$ & 6 \\
Wood dust & $1.1(0.5-2.4)$ & 9 \\
Paper dust & $2.1(1.4-3.2)$ & 32 \\
Textile dust & $1.9(1.1-3.3)$ & 22 \\
Strong acids & $1.5(0.7-3.2)$ & 9 \\
Ammonia & $1.3(0.6-2.8)$ & 9 \\
Formaldehyde & $1.6(0.7-3.6)$ & 8 \\
Engine exhaust & $1.2(0.8-1.9)$ & 28 \\
Rapid glues (Loctite $\mathbb{R})$ & $1.2(0.6-2.5)$ & 9 \\
Paint hardeners & $1.6(0.7-4.0)$ & 6 \\
Solvents & $2.1(1.4-3.0)$ & 38 \\
Work as a cleaner & $1.1(0.6-1.9)$ & 16 \\
\hline Odds &
\end{tabular}

Odds ratios according to Mantel-Haenszel, stratified for sex and age with $95 \%$ confidence intervals in parentheses. $n$ : number of exposed cases. The exposure categories are not mutually exclusive. When $>20$ cases, stratification for smoking is added.
Table 4. - Risk for asthma males and females according to occupational exposure

\begin{tabular}{|c|c|c|}
\hline \multirow[t]{2}{*}{ Exposure or occupation } & \multicolumn{2}{|c|}{ Odds ratio } \\
\hline & Males & Females \\
\hline Welding fumes & $2.0(1.2-3.3)^{*}$ & - \\
\hline Soldering & $1.1(0.5-2.3)$ & - \\
\hline Grinding & $1.5(0.8-2.8)$ & - \\
\hline Cutting fluids & $1.6(0.7-3.6)$ & - \\
\hline Mineral dust & $1.0(0.5-2.3)$ & - \\
\hline Man-made mineral fibres & $2.3(1.2-4.2)$ & - \\
\hline Asbestos & $1.9(0.9-3.8)$ & - \\
\hline Flour dust & $3.6(1.3-10.4)$ & - \\
\hline Wood dust & $1.2(0.6-2.7)$ & - \\
\hline Paper dust & $1.4(0.6-3.1)$ & $2.6(1.5-4.3)^{*}$ \\
\hline Textile dust & - & $2.1(1.2-3.8)$ \\
\hline Strong acids & $1.6(0.6-4.4)$ & - \\
\hline Ammonia & - & $1.3(0.5-3.3)$ \\
\hline Formaldehyde & - & $2.0(0.8-5.0)$ \\
\hline Engine exhaust & $1.1(0.6-1.9)^{*}$ & $1.7(0.8-3.8)$ \\
\hline Rapid glues (Loctite $(\mathbb{R})$ & $1.4(0.7-3.2)$ & - \\
\hline Paint hardeners & $1.9(0.8-4.8)$ & - \\
\hline Solvents & $2.1(1.3-3.5)^{*}$ & $2.1(1.0-4.3)$ \\
\hline Work as a cleaner & - & $1.1(0.6-2.0)$ \\
\hline
\end{tabular}

Odds ratios (Mantel-Haenszel) have been stratified for ageclass, and if $>20$ cases also for smoking, with $95 \%$ confidence intervals in parentheses. Only exposures with five exposed cases or more in each sex have been considered in the analyses. *: stratified for smoking habits.

2.6, 95\% CI 1.5-4.3) and textile dust (OR 2.1, 95\% CI $1.2-3.8)$.

In the logistic regression models, controlling for sex, age and smoking (table 5), the increased asthma risk was associated with exposure to welding fumes (OR 2.0, 95\% CI 1.5-3.4). Textile handling is often associated with exposure to formaldehyde, which originates from the finishing of textiles. However, when controlling for formaldehyde exposure, the asthma risk associated with textile dust exposure was still increased (OR 1.7, 95\% CI 1.02.9).

Table 5. - Risk for asthma according to occupational exposure from multiple logistic regression models adjusted for sex, age and smoking

\begin{tabular}{ll}
\hline Exposure & $\begin{array}{c}\text { Odds ratio } \\
\text { (95\% confidence interval) }\end{array}$ \\
\hline Construction work & \\
Welding fumes & $2.0(1.5-3.4)$ \\
Soldering & $0.7(0.3-1.5)$ \\
Man-made mineral fibres & $2.6(1.4-7.3)$ \\
Asbestos & $1.2(0.5-2.5)$ \\
Wood dust & $0.6(0.2-1.4)$ \\
Painting work & \\
Solvents & $2.2(1.4-3.7)$ \\
Ammonia & $1.0(-)$ \\
Paint hardeners & $1.0(-)$ \\
Rapid glues (Loctite $\mathbb{R})$ & $0.8(0.3-2.1)$ \\
Mechanical industry & \\
Grinding & $0.8(0.4-2.0)$ \\
Solvents & $2.1(1.3-3.3)$ \\
Engine exhaust & $1.1(0.8-2.1)$ \\
Cutting oils & $1.2(0.5-3.7)$ \\
\hline
\end{tabular}


Table 6. - Occupations in the year before asthma diagnosis among males with asthma reporting exposure to welding fumes, man-made mineral fibres (MMMF) and solvents

\begin{tabular}{|c|c|c|}
\hline Occupational exposure & Occupation & $\mathrm{n}$ \\
\hline \multirow[t]{10}{*}{ Welding fumes } & Welder & 1 \\
\hline & Filer & 1 \\
\hline & Construction worker & 2 \\
\hline & Plumber & 2 \\
\hline & Electrician & 2 \\
\hline & Sheet-metal worker & 3 \\
\hline & Machinery fitter & 4 \\
\hline & Various & 6 \\
\hline & Not stated & 4 \\
\hline & Total & 25 \\
\hline \multirow{9}{*}{ MMMF } & Carpenter & 6 \\
\hline & Machinery fitter & 2 \\
\hline & Construction worker & 2 \\
\hline & Sheet-metal worker & 1 \\
\hline & Plumber & 1 \\
\hline & Painter & 1 \\
\hline & Various & 2 \\
\hline & Not stated & 1 \\
\hline & Total & 16 \\
\hline \multirow[t]{11}{*}{ Solvents } & Carpenter & 3 \\
\hline & Machinery fitter & 9 \\
\hline & Painter & 2 \\
\hline & Electrician & 2 \\
\hline & Laboratory technician & 2 \\
\hline & Welder & 1 \\
\hline & Printer & 1 \\
\hline & Plumber & 1 \\
\hline & Various & 3 \\
\hline & Not stated & 3 \\
\hline & Total & 27 \\
\hline
\end{tabular}

The occupational titles for the male subjects reporting exposure to welding fumes, man-made mineral fibres, and solvent exposure are shown in table 6 . The occupational titles for females reporting exposure to paper dust and textile dust are presented in table 7 . The subjects exposed to welding fumes seem to correspond to a variety of mechanical workers. The subjects reporting exposure to man-made mineral fibres consisted mainly of construction workers, and the solvent-exposed subjects included a variety of manual labourers. The textile dust-exposed

Table 7. - Occupations in the year before asthma diagnosis among females with asthma reporting exposure to paper dust and textile dust

\begin{tabular}{llr}
\hline Occupational exposure & Occupation & $\mathrm{n}$ \\
\hline Paper dust & Administrative work & 14 \\
& Postal office work & 3 \\
& Nurse & 3 \\
& Cleaner & 2 \\
& Not reported & 2 \\
Textile dust & Total & 24 \\
& Textile work & 5 \\
& Textile teacher & 2 \\
& Cleaner & 2 \\
& Administrative work & 2 \\
& Nurse's assistant & 5 \\
& Not reported & 2 \\
& Total & 18 \\
\hline
\end{tabular}

females seem to have handled textiles in different situations, implying a possible exposure to textile dust. The paper dust-exposed females seem to be administrators, workers with low exposure to paper dust.

The fraction of asthma attributable to occupational exposure was $11 \%$ (95\% CI 7-14). Among males it was 14\% (95\% CI 6-19) and among females it was $10 \%$ (95\% CI 512).

\section{Discussion}

The most interesting finding in this study was the increased risk for asthma associated with occupational exposure to welding fumes and textile dust. The fraction of recent-onset asthma attributable to occupational exposures was $11 \%$.

The exposure assessment was based on self-reporting of certain types of exposures. The types of exposures listed were chosen because of an a priori hypotheses of an increased risk for asthma. A similar questionnaire has been used in a previous study, and, in the current study, the hypotheses generated in the previous study could be further investigated [11]. An increased risk associated with welding fumes, textile dust and paper dust was observed in both studies. The wording of the questions was as specific as possible, and general classes of substances such as "gas" or "dust" were avoided. This design probably increased the specificity and decreased the sensitivity of these exposure variables [15-16]. However, when the exposure prevalence is low, a high specificity is preferable when calculating relative risks in epidemiological studies [17].

The exposure information was collected retrospectively, which may have introduced some misclassification, i.e. a number of subjects may have forgotten their previous exposures. This misclassification may be important, as studies based on questionnaires are sensitive to "recall bias". Although a similar fraction of cases and controls returned their questionnaires, subjects with asthma may be more prone to report their exposures, especially if the exposure has been discussed in association with asthma. In order to decrease the misclassification of the exposure assessment, the time period of the exposures was assessed and only exposures that occurred before the diagnosis of asthma were included. To be classified as exposed the subject must report both the first and the last year of the exposure. As the exposures might have occurred several years before 1996, some subjects may have failed to report, or not reported the correct years. The crucial issue, however, is if this forgetfulness is linked to disease status, i.e. is the misclassification differential or nondifferential. It was assumed that the misclassification is mainly nondifferential, hence causing decreased risk estimates. However, regarding some exposures such as paper dust and manmade mineral-fibres, differential misclassification must be considered. If the risk for asthma was calculated without regard to the time of exposure, the risks decreased markedly. The risk for welding fumes was 1.3 (95\% CI $0.9-$ $1.8)$, for grain dust, $1.9(95 \%$ CI $1.0-3.5)$ and for paper dust exposure, 1.6 (95\% CI 1.2-2.3). These examples stress the importance of noting the temporal relations.

Smoking was not found to be a risk factor for asthma, and adjusting for smoking in this study had a minimal effect on the risk estimates for specific exposures. This was 
also the case in other population-based studies [2, 11]. Atopy was not controlled for, but other studies have found that the occupational asthma risk in population studies is not modified by an atopic state $[2,11]$. The reason for this is that the major risk factors for occupational asthma in a working population are independent of specific immunoglobulin (Ig)E-sensitization, i.e. low molecular weight agents or irritants.

A higher AP owing to occupational exposure than some recently published studies has been found in this study [2, 3], but a lower AP compared with a similar study from Singapore [1]. The AP is the fraction of observed cases that have been avoided if no-one in the population was exposed. The sum of different APs (occupation, smoking, atopy, etc.) in a population exceed $100 \%$. There are three obvious reasons for a higher AP than those of KogEvinAs et al. [2] and Fishwick et al. [3] to be reached. In the present study subjects with adult recent-onset asthma were analysed, and not a sample with prevalent asthma-cases. When Kogevinas et al. [2] restricted their asthma definition to adult-onset asthma their AP increased to at most $9 \%$. The age-span in the present population was 18-60 yrs, compared with 20-44 yrs for KogEvinas et al. [2] and FisHwick et al. [3] If the present population was restricted to 20-44 yrs, the AP was 5\%. The studies from Spain and New Zealand were from different parts of the countries, but the present population was from the largest industrialized city in Sweden. Hence, the authors consider the AP owing to occupational exposures is at least $11 \%$ among subjects with recent-onset asthma in a population aged 18-60 yrs, living in an industrialized town.

The diagnosis of asthma among the cases is considered to be valid, as it was based on a combination of clinical history and clinical physiological findings. The study included only subjects with recent-onset asthma, meaning that subjects with a previous history of asthmatic symptoms had to be free from asthma symptoms and medication for at least 5 yrs. However, asthmatic symptoms in childhood ( $<16$ yrs) were reported by $18 \%$ of the cases. In these subjects, occupational asthma can be caused by exacerbation resulting from working in polluted workplaces. On the other hand, these subjects may avoid polluted workplaces, hence introducing a negative bias. If the analyses were performed with these cases excluded, the results did not change. If any, the risk estimates increased, such as for welders the OR increased to 2.4 (95\% CI 1.5-3.9) and for grain dust the OR increased to 5.5 (95\% CI 2.1-14.2). Hence, this could be considered a study of new-onset occupational asthma.

The aim of the analysis was to study certain hypotheses regarding occupational asthma, not to cover all possible causes of occupational asthma. Hence, some relevant workplaces and agents, such as being a nurse and/or exposure to latex and psyllium, have not been proposed to the participants. Other well-known risk factors were included. Exposure to grain dust and flour dust was associated with a high risk for asthma [18]. Work with laboratory animals was not included in the final analysis because there were only four exposed cases. However, an additional analysis using unstratified data resulted in a crude OR of 18.4 (95\% CI 3.8-89.5).

Exposure to welding fumes implies exposure to respiratory irritants and fumes from different metals, such as hexavalent chromium, zinc and aluminium [19]. If the steel is painted, this further implies exposure to combustion products from burnt paint. Hence, welders are exposed to a wide variety of irritants and sensitizers, and the causative factors are generally difficult to define. Asthma has been described after welding stainless steel [20-23], and a slightly increased risk for asthma among welders has been seen in two epidemiological studies [5, 24]. However, in a review in 1991, the evidence was not considered strong enough to support a causal relation between plain steel welding and asthma onset [25]. The current study shows a relationship between exposure to welding fumes and asthma, but the causative exposure could not be pinpointed. One concern with this result is that respondents with asthma tend to over-report exposure to welding fumes in an effort to "explain" their asthma. Considering the authors previous finding of an increased risk for asthma after exposure to welding fumes [11], it is believed that welding work should be recognized as a risk factor for occupational asthma.

An increased risk for asthma among textile workers has been described in previous studies [1, 8, 26]. The occupational titles also indicate that these subjects are exposed to textile dust. However, interfering exposures must be considered. Textile dyes have been associated with asthma [27], but in this area there are no textile dye-works. Textile fabric workers are also probably exposed to dust from crude cotton, but in this area the textile mills are mainly weaving mills, and not spinning mills. Hence, misclassification between asthma and byssinosis is considered as less likely. Four studies, on different populations and using different methods, have found an increased risk for asthma among textile workers or workers exposed to textile dust. Hence, the present authors consider that this reflects a causal relation.

Exposure to high levels of paper dust has been associated with increased mortality due to obstructive airways disease [28] and decreased lung function [29, 30], but the risk for asthma was only slightly increased [31]. In the present study, the occupational titles indicate that the subjects reporting paper dust exposure experience rather low exposure to paper dust. One explanation is that asthmatics tend to over-report paper dust exposure when working in offices, workplaces in which controls do not consider themselves to be paper dust-exposed.

Man-made mineral fibres include products commonly called glass-wool, slag-wool and rock-wool. Previous studies have shown an increased prevalence of respiratory symptoms, i.e. cough and phlegm among exposed workers, but not an increased risk for asthma [32, 33]. The risk estimate in this study was rather high, even when controlling for interacting exposures. The occupational titles indicated that the exposed workers were mainly construction workers. In the authors previous study, there was no increased risk associated with man-made mineral fibres [11], and further studies are needed to determine whether the present observation reflects a causal relation or just a random finding.

An increased risk for asthma associated with self-reported exposure to solvents has previously been reported in two population-based studies $[4,5]$. In a follow-up study of painters, the incidence of airway symptoms was associated with the use of solvent-based paint [34].

In conclusion, self-reported exposure to welding fumes, man-made mineral fibres, solvents, textile dust and paper 
dust is associated with an increased risk for asthma. In respect to welding fumes and textile dust, a causal relation may exist. With solvents, increased asthma risk has also been reported by other researchers, but further studies are needed to evaluate whether this is a causal relation. In the case of exposure to man-made mineral fibres and paper dust, other interacting exposures or bias may be of importance.

\section{References}

1. Ng TP, Hong CY, Goh LG, Wong KT, Chung-Koh KT, Ling SL. Risks of asthma associated with occupations in a community-based case-control study. Am J Ind Med 1994; 25: 709-718.

2. Kogevinas M, Antó JM, Soriano JB, Tobias A, Burney P. The risk of asthma attributable to occupational exposures: a population-based study in Spain. Am J Respir Crit Care Med 1996; 154: 137-143.

3. Fishwick D, Pearce N, D'Souza W, et al. Occupational asthma in New Zealanders: a population based study. Occup Environ Med 1997; 54: 301-306.

4. Xu X, Christiani DC. Occupational exposures and physician-diagnosed asthma. Chest 1993; 104: 1364-1370.

5. Antti-Poikka M, Nordman H, Koskevuo M, Kaprio J, Jalava M. Role of occupational exposure in the development of asthma. Int Arch Occup Environ Health 1992; 64: 195-200.

6. Flodin U, Ziegler J, Jönsson P, Axelson O. Bronchial asthma and air pollution at workplaces. Scand $J$ Work Environ Health 1996; 22: 451-456.

7. Mastrangelo G, Bombana S, Priante E, Gallo A, Saia B. Repeated case-control studies as a method of surveillance for asthma in occupations. J Occup Environ Med 1997; 39: 51-57.

8. Blanc P. Occupational asthma in a national disability survey. Chest 1987; 92: 613-617.

9. Milton DK, Solomon GM, Rosiello RA, Herrick RF. Risk and incidence of asthma attributable to occupational exposure among HMO members. Am J Ind Med 1998; 33: $1-10$.

10. Fritschi L, Sierniatycki J, Richardson L. Self-assessed versus expert-assessed occupational exposures. Am J Epidemiol 1996; 144: 521-527.

11. Torén K, Järvholm B, Brisman J, Hagberg S, Hermansson B-A, Lillienberg L. A Swedish population-based casereferent study of occupational exposures and adult-onset asthma. Am J Respir Crit Care Med 1995; 151: A31 (abstract).

12. Balder B, Lindholm NB, Löwhagen O, et al. Predictors of self-assessed work ability among subjects with recent onset asthma. Respir Med 1998; 92: 729-734.

13. Miettinen O. Estimability and estimation in case-referent studies. Am J Epidemiol 1976; 103: 226-235.

14. Rothman KJ. Modern Epidemiology. Boston, Little Brown and Co., 1986.

15. Copeland KT, Checkoway H, McMichael AJ, Holbrook RH. Bias due to misclassification in the estimation of relative risk. Am J Epidemiol 1977; 105: 488-495.

16. Teschke K, Kennedy S, Olshan A. Effect of different questionnaire formats on reporting of occupational exposures. Am J Indust Med 1994; 26: 327-338.

17. Flegal KM, Brownie C, Haas JD. The effects of exposure misclassification on estimates of relative risk. Am J Epidemiol 1986; 123: 736-751.

18. Chan-Yeung M, Malo J-L. Aetiological agents in occupational asthma. Eur Respir J 1994; 7: 346-371.

19. Vandenplas O, Delwiche J-P, Vanbilsen M-L, Joly J, Roosels D. Occupational asthma caused by aluminium welding. Eur Respir J 1998; 11: 1182-1184.

20. Keskinen H, Kalliomäki PL, Alanko K. Occupational asthma due to stainless steel welding fumes. Clin Allergy 1980; 10: 151-159.

21. Dahl R, Millelsen HB. Asthma bronkiale og kromallergi udlöst af sveisning af rustfritt stal. (In Danish) Ugeskr Laeger 1982; 144: 801-802.

22. Björnerem H, Thomassen LM, Wergeland E. Sveiserastma. En kuriositet? eller-? (In Norwegian) Tidskr Nor Laegeforen 1983; 103: 1286-1288.

23. Moller DR, Brooks SM, Bernstein DI, Cassedy K, Enrione M, Bernstein IL. Delayed anaphylactoid reaction in a worker exposed to chromium. J Allergy Clin Immunol 1986; 77: 451-456

24. Wang ZP, Larsson K, Malmberg P, Sjögren B, Hallberg $\mathrm{B}-\mathrm{O}$, Wrangskog K. Asthma, lung function, and bronchial responsiveness in welders. Am J Indust Med 1994; 26 : 741-754.

25. Sferlazza SJ, Becket WS. The respiratory health of welders. Am Rev Respir Dis 1991; 143: 1134-1148.

26. Hörte LG, Torén K. Smoking adjusted mortality due to asthma in a population of Swedish working women. $\mathrm{Br} \mathrm{J}$ Indust Med 1993; 50: 575-576.

27. Thorén K, Meding B, Nordlinder R, Belin L. Contact dermatitis and asthma from reactive dyes. Contact Dermat 1986; 15: 186.

28. Thorén K, Järvholm B, Morgan U. Mortality from asthma and chronic obstructive pulmonary disease among workers in a soft paper mill: a case referent study. Br J Indust Med 1989; 46: 192-195.

29. Järvholm B, Thorén K, Brolin I, Morgan U, Bake B. Lung function among workers exposed to paper dust. $A m J$ Indust Med 1988; 14: 457-464.

30. Ericsson J, Järvholm B, Norin F. Respiratory symptoms and lung function following exposure to soft paper tissue dust. Int Arch Occup Environ Health 1988; 60: 341-345.

31. Torén K, Järvholm B, Sällsten G, Thiringer G. Asthma and asthmalike symptoms among workers exposed to paper dust. Am J Indust Med 1994; 26: 489-496.

32. Moulin JJ, Wild P, Mur JM, et al. Respiratory health assessed by questionnaire of 2024 workers involved in man-made mineral fiber production. Int Arch Occup Environ Health 1988; 61: 171-178.

33. Saracci R, Simonato L. Man made vitreous fibers and workers' health: an overview of the epidemiological evidence. Scand J Work Environ Health 1982; 8: 234-242.

34. Wieslander G, Edling C, Norbäck D. Airway symptoms among house painters in relation to exposure to volatile compounds (VOCS)-a longitudinal study. Ann Occup Hyg 1997; 41: 155-166. 